\title{
Artabotrys pachypetalus (Annonaceae), a new species from China
}

\author{
Bine Xue', Gang-Tao Wang ${ }^{2}$, Xin-Xin Zhou ${ }^{3}$, Yi Huang ${ }^{4}$, \\ Yi Tong ${ }^{5}$, Yongquan $\mathrm{Li}^{1}$, Junhao Chen ${ }^{6}$
}

I College of Horticulture and Landscape Architecture, Zhongkai University of Agriculture and Engineering, Guangzhou 510225, Guangdong, China 2 Hangzhou, Zhejiang, China 3 Key Laboratory of Plant Resources Conservation and Sustainable Utilization, South China Botanical Garden, Chinese Academy of Sciences, Guangzhou 510650, China 4 Guangzhou Linfang Ecology Co., Ltd., Guangzhou, Guangdong 510520, China 5 School of Chinese Materia Medica, Guangzhou University of Chinese Medicine, Guangzhou 510006, China 6 Singapore Botanic Gardens, National Parks Board, 1 Cluny Road, 259569, Singapore

Corresponding author: Junhao Chen (patrickjunhao@gmail.com)

Academic editor: T.L.P. Couvreur | Received 16 February 2021 | Accepted 3 May 2021 | Published 27 May 2021

Citation: Xue B, Wang G-T, Zhou X-X, Huang Y, Tong Y, Li Y, Chen J (2021) Artabotrys pachypetalus (Annonaceae), a new species from China. PhytoKeys 178: 71-80. https://doi.org/10.3897/phytokeys.178.64485

\begin{abstract}
Artabotrys pachypetalus sp. nov. is described from Guangdong, Guangxi, Guizhou, Hunan and Jiangxi in China. A detailed description, distribution data, along with a color plate and a line drawing are provided. In China, specimens representing this species were formerly misidentified as A. multiflorus or $A$. hongkongensis (= A. blumei). Artabotrys blumei typically has a single flower per inflorescence, whereas both Artabotrys pachypetalus and $A$. multiflorus have multiple flowers per inflorescence. In addition, $A$. pachypetalus is readily distinguished from $A$. multiflorus in having thicker and shorter petals, and connivent and somewhat trigonal or terete inner petal blades. Artabotrys pachypetalus is most similar to A. punctulatus because both have multi-flowered inflorescences and similar petal length, but $A$. pachypetalus differs in having cream petals in vivo, connivent inner petal blades, and a short, raised rim above the inner petal claw. Artabotrys multiflorus should be excluded from the flora of China because none of the Chinese specimens of Artabotrys collected so far fall within the variation of $A$. multiflorus.
\end{abstract}

\section{Keywords}

Annonaceae, Artabotrys, morphology, South China, taxonomy

Copyright Bine Xue et al. This is an open access article distributed under the terms of the Creative Commons Attribution License (CC BY 4.0), which permits unrestricted use, distribution, and reproduction in any medium, provided the original author and source are credited. 


\section{Introduction}

Artabotrys R.Br. is one of the largest genera in the Annonaceae, with over 100 species of woody climbers distributed in Africa (including Madagascar) and Asia (Chen et al. 2019; Rainer and Chatrou 2021). Among the lianescent genera of the Annonaceae, Artabotrys is distinctive in possessing hooked inflorescence axes that facilitate climbing (Posluszny and Fisher 2000). Although the persistent inflorescence hook is a synapomorphy for the genus, identification at the species level is often complex. In general, the flowers of Artabotrys possess a uniform structure characterised by a tightly enclosed floral chamber (Chen et al. 2019, 2020). Both the outer and inner petals are concave at the base, with an expanded, generally flattened (sometimes terete or triquetrous) blade above the concave base. In addition, the inner petals have a projecting rim between its blade and the concave base (see fig. 9d in Chen et al. 2020); the elaborate rims of the three inner petals are tightly connivent, forming a dome around the reproductive organs. The concave base of the petals has been traditionally referred to as the 'claw' by Sinclair (1955) and widely followed by recent workers (e.g., Turner 2012; Prabhu et al. 2015; Turner and Utteridge 2015; Chen et al. 2018; Chen and Eiadthong 2020), although the term 'claw' is also used (in a strict sense) to refer to the narrowed, stalk-like, basal portion of the inner petals of other genera, e.g. Mitrephora (Blume) Hook.f. \& Thomson, Monodora Dunal and Pseuduvaria Miq. (Sinclair 1955; Su and Saunders 2006; Couvreur 2009; Weerasooriya and Saunders 2010). The terms 'claw' and 'blade' have been explained in detail by Chen et al. (2020) in the context of the pollination biology of Artabotrys. To date, eight Artabotrys species have been recorded in China, viz. A. fragrans Jovet-Ast, A. hainanensis R.E.Fr., $A$. hexapetalus (L.f.) Bhandari, A. blumei Hook.f. \& Thomson (recorded as A. hongkongensis Hance), A. multiflorus C.E.C. Fisch., A. pilosus Merr. \& Chun, A. punctulatus C.Y.Wu ex S.H.Yuan, A. rhynchocarpus C.Y.Wu ex S.H.Yuan (Li and Gilbert 2011).

During our field exploration in Yangchun City in Guangdong Province, we collected an Artabotrys species with multi-flowered inflorescences. Morphological comparison with herbarium specimens from China revealed that the newly collected specimen is conspecific with many specimens that were previously identified as $A$. multiflorus or A. hongkongensis. However, our Yangchun collections (and the abovementioned specimens) do not match type specimens or descriptions of $A$. multiflorus and $A$. hongkongensis. Originally described from Myanmar (Fischer 1937; Kress et al. 2003; Turner 2015), Artabotrys multiflorus also occurs in adjacent forests in Thailand (Chen et al. 2018; Chen and Eiadthong 2020) and is distinct in having multiple flowers per inflorescence and lanceolate petals (Fischer 1937; Chen and Eiadthong 2020). In China, A. multiflorus was first incorrectly recorded by $\mathrm{Xu}$ and $\mathrm{Li}(1985)$ based on three collections from Guizhou Province (Z.R. Xu. L1224, S827, L437, SYS). Subsequently, more specimens in China were misidentified as A. multiflorus. Thus, Li and Gilbert (2011) recorded this species in the Flora of China with a quite wide distribution in Guangdong, Guangxi, Guizhou and Yunnan. Originally described from Hong 
Kong, A. hongkongensis is also reportedly widespread in China, where it is known from Hunan, Guangdong, Guangxi, Yunnan, Guizhou and Hainan provinces (Li and Gilbert 2011); it is also recorded in Vietnam (Bân 2000). This species usually bears a single-flowered inflorescence (rarely two-flowered). However, this name has now been synonymized with $A$. blumei Hook.f. \& Thomson (Turner 2018).

Apart from Yangchun, flowering individuals are also found in Ruyuan in Guangdong Province, as well as Mulun National Nature Reserve in Guangxi. Based on detailed comparisons of available living material as well as herbarium specimens, we confirm that our collections and many specimens misidentified as A. multiflorus and A. hongkongensis in China represent a new species described here as Artabotrys pachypetalus. In addition, $A$. multiflorus is not present in China, as none of the Chinese specimens of Artabotrys collected so far fall within the variation of $A$. multiflorus.

\section{Materials and methods}

Physical and scanned herbarium specimens of Artabotrys from 15 Chinese herbaria (BNU, CCNU, GF, GFS, GZAC, GXMG, GXMI, GZTM, HGAS, HITBC, IBK, IBSC, KUN, PE and SYS; acronyms according to Thiers 2021) were studied in detail and compared with the type specimens and descriptions of $A$. multiflorus, A. blumei and other similar species from China and Indochina. Fresh material was collected from Chun-wan Town, Yangchun City of Guangdong, China. The morphological study was based on fresh material and herbarium specimens, but the measurements in the description below are based on dried material. The distribution, habitat and phenology of the new species are based on field observations and specimen records.

\section{Taxonomy}

Artabotrys pachypetalus B.Xue \& Junhao Chen, sp. nov. urn:Isid:ipni.org:names:77217250-1

Figs 1, 2

Chinese name. Hou ban ying zhua hua (厚瓣鹰爪花)

Diagnosis. Similar to Artabotrys punctulatus C.Y.Wu ex S.H.Yuan in having multiflowered inflorescences and similar outer and inner petal length (9-20 mm long), but differs in having non-punctate (vs. densely punctate) abaxial leaf lamina, cream (vs. beige, maroon-tinged) petals in vivo, connivent (vs. spreading) inner petal blades in vivo, a short, ca. $1 \mathrm{~mm}$ long (vs. an elongate, ca. $5 \mathrm{~mm}$ long) raised rim above the inner petal claw, and thick pericarp (2-3 mm thick vs. less than $1 \mathrm{~mm}$ thick).

Type. China. Guangdong Province, Yangchun, Chun-wan Town, Zi-you Village, Ma-tang, alt. 110 m, limestone, 08 Apr. 2019, X.X. Zhou, G.T. Wang \& Y.N. Guo 0028 (holotype: IBSC [barcode no. IBSC0861926]; isotypes: KUN, SING). 

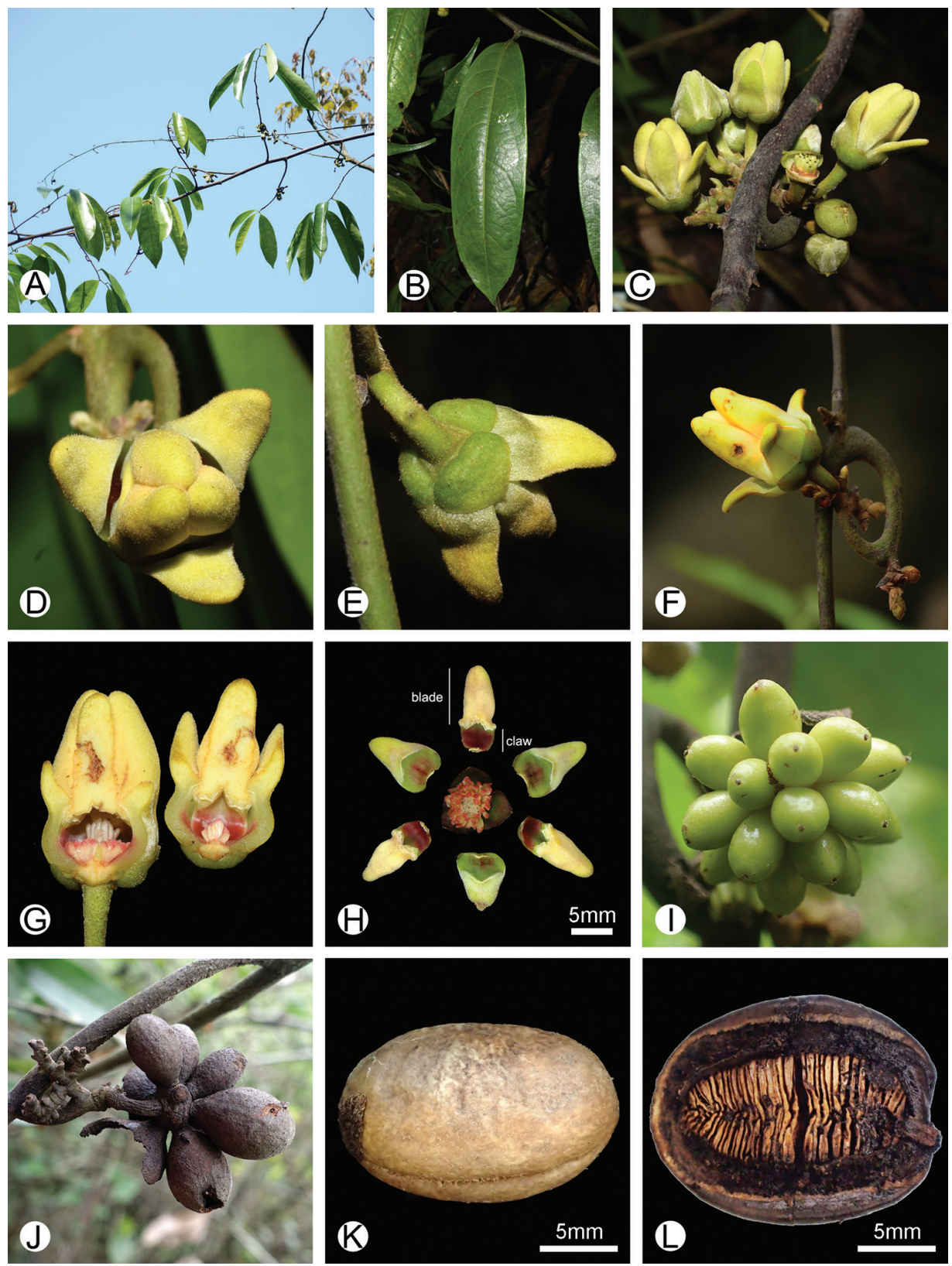

Figure I. Photographs of Artabotrys pachypetalus sp. nov. A habit B adaxial leaf surface, showing the raised midrib $\mathbf{C}$ hooked inflorescence with many loosely clustered flowers $\mathbf{D}$ apical view of the flower $\mathbf{E}$ basal view of the flower $\mathbf{F}$ lateral view of the flower $\mathbf{G}$ longitudinal section of the flower, showing the clavate stigma and orange-red stamen connective apex $\mathbf{H}$ dissected flower, showing three sepals, three outer petals and three inner petals, and many carpels and stamens ( $Y$. Huang 341, IBSC) I developing young fruit with many monocarps (B. Xue XB342, IBSC) J dried fruit on old branch (B. Xue XB342, IBSC) $\mathbf{K}$ seed (B. Xue XB342, IBSC) L longitudinal section of the seed, showing lamelliform endosperm ruminations (B. Xue XB342, IBSC). Photos: Yi Huang (A, H); Gang-Tao Wang (B-E, G); Yi Tong (F); Bine Xue (I-L). 


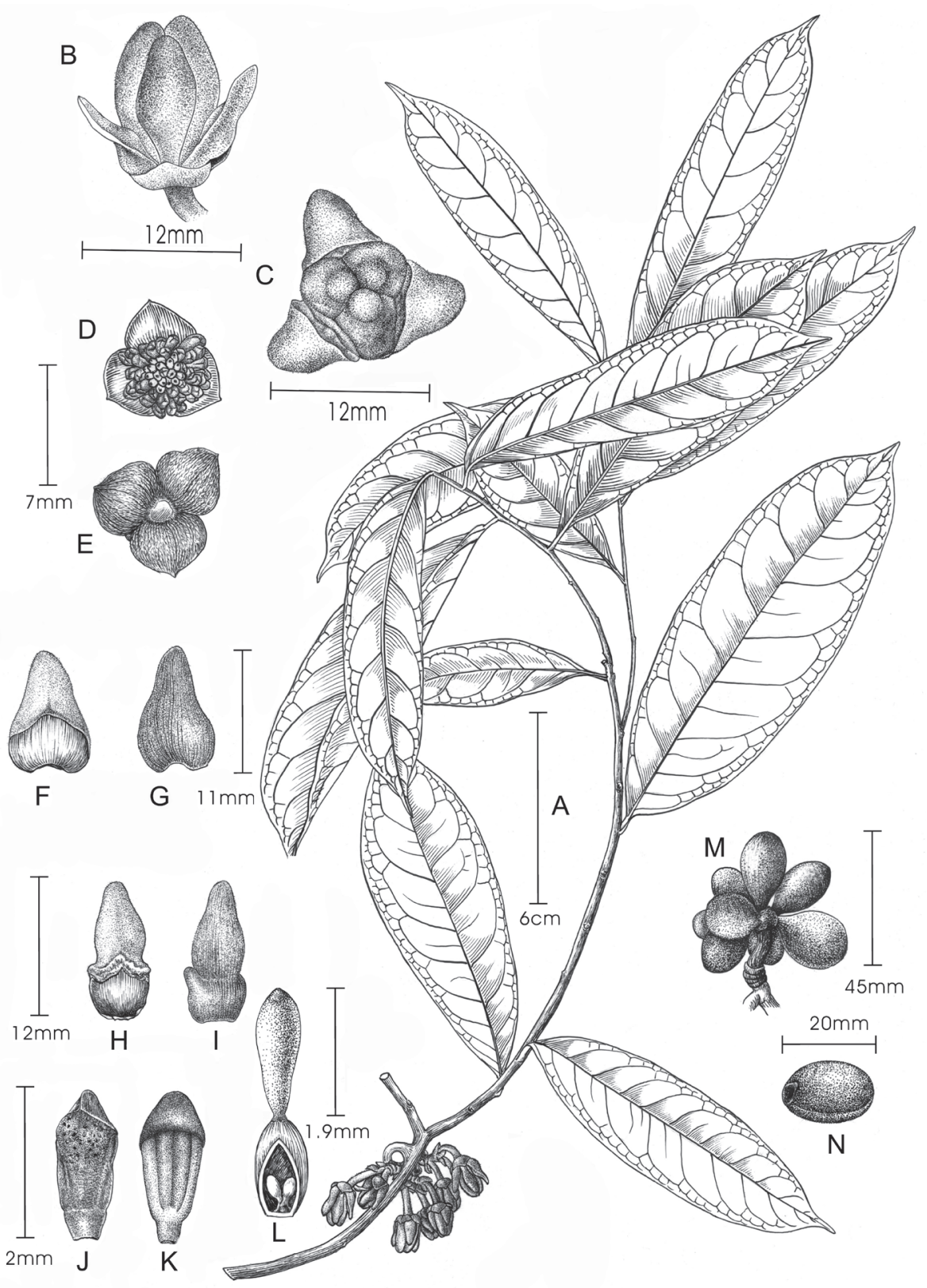

Figure 2. Illustration of Artabotrys pachypetalus sp. nov. A flowering branch, showing the hooked inflorescence with multiple flowers $\mathbf{B}$ lateral view of the flower $\mathbf{C}$ adaxial view of the flower, showing three outer petals and three inner petals forming a closed floral chamber $\mathbf{D}$ adaxial view of the sepals and torus with stamens and carpels $\mathbf{E}$ abaxial view of the sepals $\mathbf{F}$ adaxial view of the outer petal $\mathbf{G}$ abaxial view of the outer petal $\mathbf{H}$ adaxial view of the inner petal $\mathbf{I}$ abaxial view of the inner petal $\mathbf{J}$ adaxial view of the stamen, showing the rounded connective apex with a sharp edge $\mathbf{K}$ abaxial view of the stamen, showing four thecae $\mathbf{L}$ carpel, showing the clavate stigma and two basal ovules $\mathbf{M}$ immature fruit $\mathbf{N}$ seed. Drawn by Yun-Xiao Liu, X.X. Zhou, G.T. Wang \& Y.N. Guo 0028 (A-L); B. Xue XB342 (M, N). 
Description. Climbers ca. $7 \mathrm{~m}$ tall. Twigs drying brown, glabrous to sparsely appressed-pubescent when young. Leaf laminas chartaceous, $10-16 \mathrm{~cm}$ long, $3.5-5.0 \mathrm{~cm}$ wide, length:width ratio 3-4(-5), narrowly oblong, apex acute or acuminate to cuspidate, base cuneate, glabrous both ab- and adaxially; midrib appressed-pubescent abaxially, glabrous adaxially, raised on both surfaces; secondary veins 8-13 pairs per leaf, impressed adaxially, raised abaxially; tertiary venation reticulate, visible on both surfaces; petioles 3-5 mm long, ca. $1 \mathrm{~mm}$ in diameter, glabrous to sparsely appressed-pubescent, drying with transverse striations. Inflorescence axis recurved, laterally compressed, hook-like, with 6-10 flowers; flowering pedicels 6-15 mm long, ca. $1 \mathrm{~mm}$ in diameter, densely spreading-pubescent. Sepals 3, free, coriaceous, valvate at base, ca. $5 \mathrm{~mm}$ long, ca. $5 \mathrm{~mm}$ wide, triangular, glabrous adaxially, sparsely appressed-pubescent abaxially. Petals 6, in two whorls of 3 inner and 3 outer petals, free, valvate, coriaceous when dry, cream in vivo, with distinct upper blade and concave base. Outer petals 3, 9-14 mm long; blades spreading, ca. 5-9 mm long, 3-7 mm wide, ca. $1 \mathrm{~mm}$ thick, ovate, densely appressed-pubescent both ab- and adaxially, apex rounded; claws 4-5 mm long, 4-8 $\mathrm{mm}$ wide, densely appressed-pubescent abaxially, glabrous adaxially. Inner petals 3, 11$17 \mathrm{~mm}$ long; with a short, ca. $1 \mathrm{~mm}$ long raised rim above the claw; blades connivent, 7-11 mm long, 4-6 mm wide, ca. $2 \mathrm{~mm}$ thick, somewhat trigonal or terete in vivo, densely appressed-pubescent both ab- and adaxially, apex rounded; claws ca. 4-6 mm long, 3-5 mm wide, densely appressed-pubescent abaxially, glabrous adaxially, tinged orange-red at the very base in vivo. Stamens extrorse, ca. 50-60 per flower, ca. $2 \mathrm{~mm}$ long, ca. $1 \mathrm{~mm}$ wide; apex of connectives rounded, with a sharp edge adaxially, orange red in vivo. Carpels 8-20 per flower, ca. $3.5 \mathrm{~mm}$ long, glabrous; ovaries ellipsoid, ca. $1.5 \mathrm{~mm}$ long, ca. $0.6 \mathrm{~mm}$ wide, glabrous; ovules 2, basal; stigmas $1.5-2 \mathrm{~mm}$ long, cylindrical to slightly clavate, glabrous. Fruiting pedicels $10-20 \mathrm{~mm}$ long, ca. $3 \mathrm{~mm}$ in diameter, subglabrous. Monocarps 8-20 per fruit, unripe monocarps in vivo light green, at maturity unknown, drying black, 25-30 mm long, 15-22 mm wide, ellipsoid, glabrous, subsessile or with stipes up to ca. $2 \mathrm{~mm}$ long, apex rounded, pericarp 2-3 $\mathrm{mm}$ thick. Seeds 2 per monocarp, light yellow, smooth, plano-convex, 16-20 mm long, 12-14 mm wide, $10-12 \mathrm{~mm}$ thick, raphe depressed, endosperm ruminations lamelliform.

Etymology. The specific epithet 'pachypetalus' alludes to the thick inner petals.

Phenology. Flowering in April; fruiting in August to December.

Distribution and habitat. Guangdong, Guangxi, Guizhou, Hunan and Jiangxi (Fig. 3), at 100-1400 m elev, mainly growing on limestone.

Additional specimens examined (Paratypes). ChInA. Guangdong: Yangchun City, Chun-wan Town, Zi-you Village, Ma-tang, alt. 110 m, limestone, 13 Apr. 2020, Y. Huang 341 (IBSC, SING); ibid., 19 Apr. 2020, B. Xue XB342, XB343 (IBSC, SING); Ru-yuan Hsien, 21 Oct. 1939, S.K. Lau 29060 (IBSC, PE); Ru-yuan Hsien, Da-qiao Town, Da-fu village, forest valley, alt. 550 m, 13 Apr. 2013, L. Wu \& Y. Tong 3234 (BNU). Guangxi: Feng-shan Hsien, Qiao-yin Town, Ba-la-hou Mountain, limestone, forest edge, alt. 940 m, 3 Mar. 2013, B.Y. Huang, X.Y. Hu \& J.J. Yao 451223130331025LY (GXMG); Qi-cheng Hisen, Cui-ping Mountain, alt. 270 m, limestone, 5 May 1983, C.Z. Gao \& A.Y. Lan 61263 (GXMI); Na-po Hisen, Nong-bu, alt. 1200 m, limestone, 02 May 1981, Ding Fang et al. 25102 (GXMI). Guizhou: Li-bo Hsien, Mao-lan, 21 


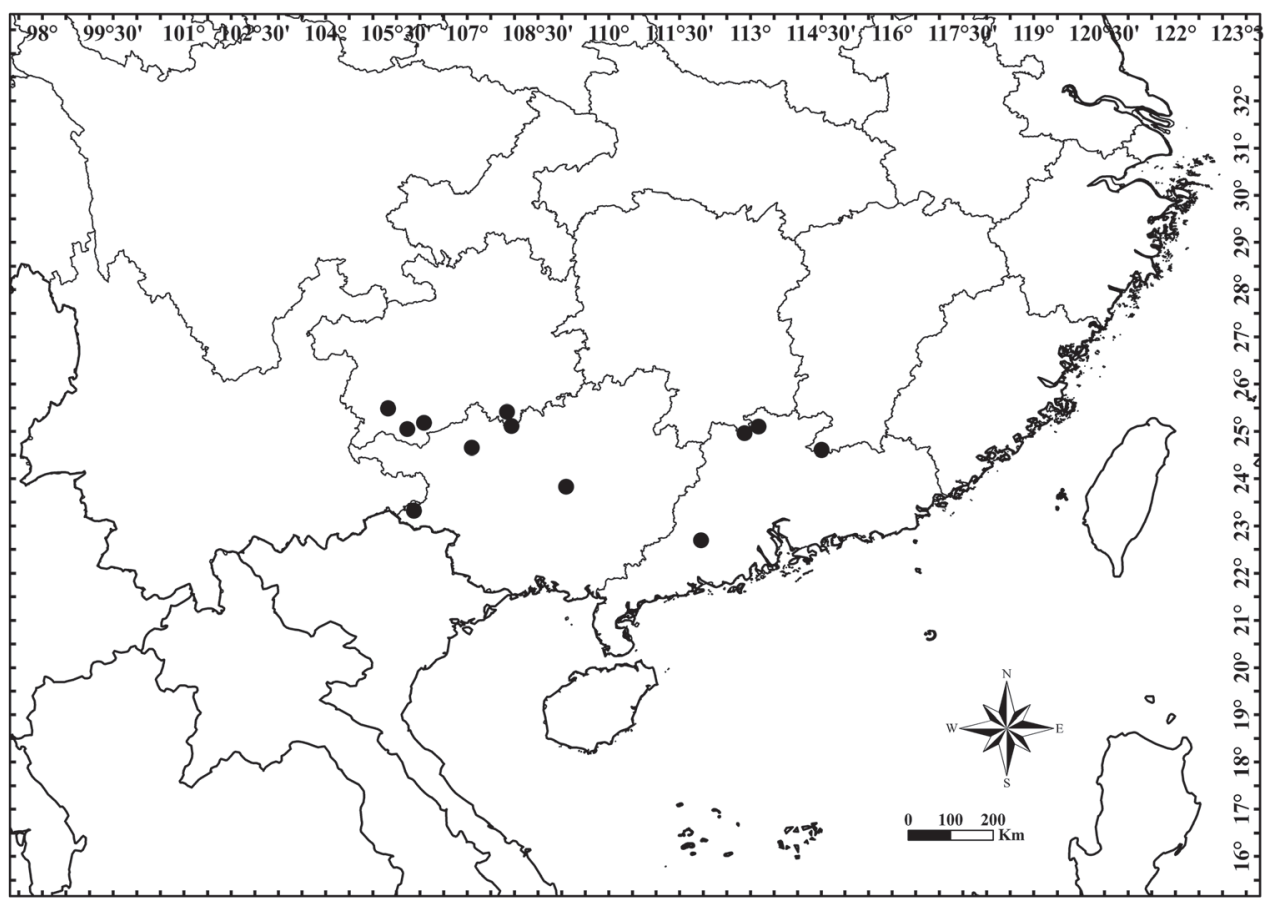

Figure 3. Distribution of Artabotrys pachypetalus sp. nov.

Apr. 1981, J.Q. Zhang 1144 (CCNU, GF, GZAC); ibid., alt. 730 m, 8 May 1981, R.B. Jiang 81-0080 (GF, IBSC); ibid., 8 May 1981, R.B. Jiang 80 (CCNU); ibid., 8 May 1981, M.Z. Yang 810247 (HGAS); ibid., alt. 750 m, 7 Mar. 1982, Y.K. Li 10039 (IBSC); ibid., alt. 710 m, 6 Sep. 1982, Y.K. Li 10462 (HGAS); ibid., alt. 800-1000 m, limestone, 03 Apr. 1984, Z.R. Xu L1224 (IBSC); ibid., 26 Apr. 1984, K.M. Lan 840097 (GFS, GZAC); ibid., 02 May 1984, K.M. Lan 841268 (GFS, GZAC); ibid., 2 May 2005, Q.W. Sun 0505019 (GZTM); Xing-ren Hsien, alt. 1300 m, 28 Jun. 1986, C.Z. Dang \& P. Dang 156 (PE); Ce-heng Hsien, 21 May 1977, anonymous 071, 77-1635 (HGAS); ibid., alt. 1400 m, 5 Sep. 1958, Z.Y. Cao 0575 (PE); Wang-mo Hsien, Chengguan, forest valley, 15 May 1977, anonymous 77-1594 (HGAS); ibid., 15 May 1977, C.Z. Dang 030 (HGAS). Hunan: Yi-zhang Hsien, Mang Mountain, forest valley, alt. 430 m, 16 Oct. 1942, S.H. Chun 2490 (IBSC, IBK). Jiangxi: Ganzhou City, Long-nan Hsien, Jiu-lian Mountain, limestone, alt. 596 m, 05 Apr. 2021, J.Y. Xu, L.X. Yuan, Y.R. Wang, J.R. Chen JLS-304 (SYS); ibid., 09 Jun. 1970, Group-236 0852 (PE).

\section{Discussion}

Artabotrys pachypetalus is similar to A. multiflorus in having multiple flowers per inflorescence (Figs 1,2), but the two species can readily be distinguished by their disparate petal morphology. The petals of A. multiflorus are $18-30 \mathrm{~mm}$ long, and 2-5 $\mathrm{mm}$ wide (Fischer 1937; Chen and Eiadthong 2020) whereas the petals of $A$. pachypetalus 
are much shorter (9-17 $\mathrm{mm}$ long, 3-8 $\mathrm{mm}$ wide). The petals of $A$. pachypetalus are also considerably thicker (1-2 mm thick when dry) than those of $A$. multiflorus (less than $1 \mathrm{~mm}$ thick when dry). In addition, the inner petal blades of $A$. pachypetalus are connivent and somewhat trigonal or terete whereas the inner petal blades of $A$. multiflorus are spreading and planar. $\mathrm{Xu}$ and $\mathrm{Li}$ (1985) recorded A. multiflorus in China based on a few collections from Li-bo Hsien, Guizhou Province (Z.R. Xu L1224, S827, L437, SYS). We failed to locate these specimens in SYS, but found a duplicate of Z.R. Xu L1224 in IBSC as well as many other collections from the same locality, i.e., Mao-lan National Nature Reserve, Guizhou Province, and hence were able to confirm that they are conspecific with the new species described that we collected in Guangdong and Guangxi. The misidentification probably arose in the absence of careful comparison against the type specimens of $A$. multiflorus.

Some specimens representing $A$. pachypetalus are also misidentified with the name A. hongkongensis in China, which is now a synonym of $A$. blumei (Turner 2018). The distinction between these two species is quite straightforward: the inflorescence of $A$. blumei usually consists of a single flower or rarely two (Li and Gilbert 2011), whereas that of $A$. pachypetalus has 6-10 co-occurring flowers (Figs 1C, F, 2A). Additionally, A. blumei can be distinguished by having planar (vs. somewhat trigonal or terete), spreading (vs. connivent) inner petal blades, subglabrous (vs. sparsely to densely pubescent) pedicels and abaxial surface of sepals, and thin pericarp ( $<1 \mathrm{~mm}$ thick vs. $2-3 \mathrm{~mm}$ thick).

Although A. pachypetalus is most similar to $A$. punctulatus, it has not been confused with the latter. This is probably because $A$. punctulatus is restricted to the montane forests of Yunnan in China and is characterized by densely punctate abaxial leaf lamina. The similarities and differences between the two species are stated in the diagnosis.

Besides the above-mentioned species, A. pachypetalus is also similar to Artabotrys hienianus Bân from Vietnam, both with multiple small hairy flowers per inflorescence (Bân 2000). The two species differ, however, in the number of the flowers per inflorescence, petiole length, leaf shape, and thickness of the pericarp. The inflorescence of A. hienianus has more flowers borne on shorter pedicels $(5-6 \mathrm{~mm})$, leading to densely clustered flowers on the inflorescence (Bân 2000), whereas that of $A$. pachypetalus has fewer flowers borne on longer pedicels (6-15 mm, Figs 1C-F, 2A), leading to loosely clustered flowers on the inflorescence (Figs 1C, 2A). Artabotrys hienianus has longer and broader leaves $(12-17 \times 5-6 \mathrm{~cm})$, whereas $A$. pachypetalus has smaller and narrower leaves $(10-16 \times 3.5-5 \mathrm{~cm})$. In addition, A. hienianus has a thin pericarp (Bân 2000), whereas that of $A$. pachypetalus is quite thick (2-3 mm thick) (Fig. 1L).

\section{Acknowledgements}

This research was supported by a grant from National Natural Science Foundation of China (Grant no. 31872646) awarded to Bine Xue and Forestry Scientific Technology Innovation Project of Guangdong Province (No.2020KJCX010). We are grateful to the curators of BNU, CCNU, GF, GFS, GZAC, GXMG, GXMI, GZTM, HGAS, 
HITBC, IBK, IBSC, KUN, PE and SYS for permission to access their collections. Thanks are also given to Ya-Nan Guo and Wei Guo for field work assistance, Yun-Xiao Liu for the excellent line drawing, Yun-Yun Shao for preparing Fig. 1, Bao-You Huang for sharing his photographs of Artabotrys collection in Guangxi, Jun-Yan Xu for sharing his photographs of Artabotrys collection in Jiangxi, and Lars Chatrou and Thomas Couvreur for constructive comments on an earlier version of our manuscript.

\section{References}

Bân NT (2000) Annonaceae. In: Bân NT, Ly TD, Khanh TC, Loc PK, Thin NN, Tien NV, Khoi NK (Eds) Flora of Vietnam (Vol. 1). Science \& Technics Publishing House, Hanoi, 5-341. [In Vietnamese]

Chen J, Eiadthong W (2020) New species and new records of Artabotrys (Annonaceae) from peninsular Thailand. PhytoKeys 151: 67-81. https://doi.org/10.3897/phytokeys.151.51643

Chen J, Chalermglin P, Saunders RMK (2018) Two new species and two new records of Artabotrys (Annonaceae) from Thailand. PhytoKeys 95: 71-81. https://doi.org/10.3897/phytokeys. 95.23434

Chen J, Thomas DC, Saunders RMK (2019) Geographic range and habitat reconstructions shed light on palaeotropical intercontinental disjunction and regional diversification patterns in Artabotrys (Annonaceae). Journal of Biogeography 46(12): 2690-2705. https:// doi.org/10.1111/jbi.13703

Chen J, Liu MF, Saunders RMK (2020) Contrasting floral biology of Artabotrys species (Annonaceae): Implications for the evolution of pollinator trapping. Plant Species Biology 35(3): 210-223. https://doi.org/10.1111/1442-1984.12273

Couvreur TLP (2009) Monograph of the African syncarpous genera Isolona and Monodora (Annonaceae). Systematic Botany Monographs 87: 1-150.

Fischer CEC (1937) Contributions to the Flora of Burma: XIII. Bulletin of Miscellaneous Information, Royal Botanic Gardens, Kew 1937(8): 436-440. https://doi.org/10.2307/4107101

Kress WJ, DeFilipps RA, Farr E, Kyi DYY (2003) A checklist of the trees, shrubs, herbs, and climbers of Myanmar. Contributions from the United States National Herbarium 45: $1-590$.

Li PT, Gilbert MG (2011) Annonaceae. In: Wu ZY, Raven PH, Hong DY (Eds) Flora of China (Vol. 19). Science Press, Beijing \& Missouri Botanical Garden Press, St. Louis, 672-713.

Posluszny U, Fisher JB (2000) Thorn and hook ontogeny in Artabotrys hexapetalus (Annonaceae). American Journal of Botany 87(11): 1561-1570. https://doi.org/10.2307/2656731

Prabhu S, Sathiyaseelan R, Aron S, Murugan C (2015) A review of the genus Artabotrys R.Br. (Annonaceae) from Andaman and Nicobar Islands, with a new record for India. Indian Journal of Forestry 38(2): 159-164.

Rainer H, Chatrou LW (2021) AnnonBase: Annonaceae GSD (version Jan 2014). In: Roskov Y, Abucay L, Orrell T, Nicolson D, Flann C, Bailly N, Kirk P, Bourgoin T, DeWalt RE, Decock W, De Wever A (Eds) Species 2000 \& ITIS Catalogue of Life. www.catalogueoflife.org [accessed 30 Mar. 2021] 
Sinclair J (1955) A revision of the Malayan Annonaceae. Gardens' Bulletin Singapore 14: 149-516. Su YCF, Saunders RMK (2006) Monograph of Pseuduvaria. Systematic Botany Monographs 79: 1-204.

Thiers B (2021) Index Herbariorum: A Global Directory of Public Herbaria and Associated Staff. http://sweetgum.nybg.org/science/ih/ [accessed 1 Feb. 2021]

Turner IM (2012) Annonaceae of Borneo: A review of the climbing species. Gardens' Bulletin (Singapore) 64: 371-479.

Turner IM (2015) A conspectus of Indo-Burmese Annonaceae. Nordic Journal of Botany 33(3): 257-299. https://doi.org/10.1111/njb.00689

Turner IM (2018) Annonaceae of the Asia-Pacific region: Names, types and distributions. Gardens' Bulletin (Singapore) 70(2): 409-744. https://doi.org/10.26492/gbs70(2).2018-11

Turner IM, Utteridge TMA (2015) Artabotrys byrsophyllus and A. tipuliferus spp. nov. (Annonaceae) from Peninsular Malaysia and Thailand. Nordic Journal of Botany 33(5): 562-566. https://doi.org/10.1111/njb.00791

Weerasooriya AD, Saunders RMK (2010) Monograph of Mitrephora (Annonaceae). Systematic Botany Monographs 90: 1-167.

Xu ZR, Li PT (1985) Some new plants from Guizhou in China. Bulletin of Botanical Research 5: 129-132. 